\title{
THE INFLUENCE OF THE ECONOMIC COUNTRY CONDITIONS ON THE PREFERENCES OF SUSTAINABLE DEVELOPMENT GOALS IN METALLURGICAL AND MINING COMPANIES
}

\author{
${ }^{1}$ Radim LENORT, ${ }^{1}$ Pavel WICHER, ${ }^{2}$ František ZAPLETAL \\ ${ }^{1}$ VSB - Technical University of Ostrava, Faculty of Materials Science and Technology, Ostrava, \\ Czech Republic,EU, radim.lenort@vsb.cz, pavel.wicher@vsb.cz \\ ${ }^{2}$ VSB - Technical University of Ostrava, Faculty of Economics, Ostrava, Czech Republic, EU, \\ frantisek.zapletal@vsb.cz
}

https://doi.org/10.37904/metal.2021.4284

\begin{abstract}
Today, the sustainable development goals adopted by United Nations belong to the basic pillars of sustainable business strategies of all industrial companies, including metallurgical and mining. However, their preferences often differ significantly in different companies around the world. One of the reasons for the different preferences may be the economic country conditions. The aim of the paper is to verify the hypothesis that the preferences of individual sustainable development goals in metallurgical and mining companies strongly depend on the economic country conditions in which these companies operate. The PROMETHEE ranking method and its GAIA tool were used as the main research methodology. The obtained results led to the confirmation of the above hypothesis and the definition of the goals most preferred in companies operating in the G7 countries, developed economies, and developing economies.
\end{abstract}

Keywords: Sustainable development goals, metallurgical and mining companies, economic country conditions, PROMETHEE method, GAIA tool

\section{INTRODUCTION}

Today, sustainability is becoming an integral part of the strategy of many metallurgical and mining companies. Legislation in different parts of the world also makes a significant contribution to this. For example, the Directive 2014/95/EU of the European Parliament and of the Council as regards disclosure of non-financial and diversity information (also called as Non-Financial Reporting Directive) introduced sustainability reporting obligations for approximately 11,700 large public-interest companies and groups with more than 500 employees across the EU [1]. The current state of research into the Directive discussed Korca and Costa [2]. The Directive was introduced by European Union in compliance with Sustainable Development Goals (SDGs) adopted by United Nations Member States in 2015 (SDG target 12.6) [3]. Therefore, SDGs are naturally integrated into sustainable reporting [4], including companies from the metallurgical and mining industry across the world. The aim of the paper is to analyse the SDGs preferences in the metallurgical and mining industry and verify the hypothesis that the preferences of individual SDGs strongly depend on the economic country conditions in which these companies operate.

\section{LITERATURE REVIEW}

United Nations Member States adopted 17 SDGs as the key part of The 2030 Agenda for Sustainable Development [5]: (1) No poverty, (2) Zero hunger, (3) Good health and well-being, (4) Quality education, (5) Gender equality, (6) Clean water and sanitation, (7) Affordable and clean energy, (8) Decent work and economic growth, (9) Industry, innovation and infrastructure, (10) Reduced inequalities, (11) Sustainable cities 
and communities, (12) Responsible consumption and production, (13) Climate action, (14) Life below water, (15) Life on land, (16) Peace, justice and strong institutions, (17) Partnerships for the goals.

Business worldwide can play a crucial role in the advancement of The 2030 Agenda for Sustainable Development. With the setting of the SDGs, the role of business in economic, social and environmental development has never been more imperative [6]. According to Yamane and Kaneko [7] awareness of SDGs is constantly increasing not only among companies but especially among their stakeholders. Also Van der Waal and Thijssens [8] state that the SDGs stress the necessity of businesses' active participation, appealing for their creativity and innovation to create value for the common good. However, preferences of SDGs across the business very often differ significantly. The paper builds on research conducted by Lenort, et al. [9], which analysed the SDGs preferences in the metallurgical and mining industry in terms of geographical location of individual companies. It aims to extend this analysis to an economic country conditions perspective.

\section{METHODOLOGICAL BASE}

PROMETHEE belongs to the family of multi-criteria decision-making methods based on special, so called outranking relations. In general, PROMETHEE covers several algorithms for various multi-criteria problem [10]. In this paper, we will use only the graphical analysis GAIA (Graphical Analysis for Interactive Aid) to explore the relationships among the criteria and alternatives and get the performance profiles of the alternatives. Therefore, just the corresponding theoretical background is provided further.

First, let us briefly recall the ranking algorithm using a general decision-making problem with $\mathrm{n}$ criteria (set $N$ ) and $\mathrm{m}$ alternatives (set $M$ ). All PROMETHEE algorithms starts with the pairwise comparison of alternatives $A_{i}, A_{j}$ in terms of each individual criterion $k \in N$. To do this, a preference function $p_{k}$, which assigns the preference degree $P_{k}\left(A_{i}, A_{j}\right) \in[0,1]$ to the difference in performance values of the compared alternatives, must be chosen (the preference degree describes how strongly a decision-maker prefers $A_{i}$ to $A_{j}$ ). This choice has to be done with respect to the both data type and range of a criterion. In general, the preference function must be non-decreasing (the greater difference in performance, the stronger preference in favour of the better alternative) and with $p_{k}(x)=$ 0 for $x \leq 0$ (the worse-performing alternative cannot be preferred). The authors of the method recommended the linear or Gaussian shape of the preference function to handle quantitative data, see Figure 1 [10].


Figure 1 Linear and Gaussian preference function's shape

For the purpose of the GAIA plane, the preference degrees must be aggregated into so called single-criterion net flows, which express how much better an alternative performs in comparison with all others in terms of the given criterion:

$$
\phi_{k}\left(A_{i}\right)=\frac{1}{m-1} \sum_{i=1, A_{i} \neq A_{j}}^{m}\left(P_{k}\left(A_{i}, A_{j}\right)-P_{k}\left(A_{j}, A_{i}\right)\right), \quad \forall k \in N, \forall i \in M .
$$

Then, each alternative is given with $n$-dimensional vector of the flows. To display the alternatives graphically onto the plane, the PCA (Principal Component Analysis) method is applied, see Brans and De Smet [11]. Because the GAIA plane provides only the projection of the real problem, it is necessary to check the quality of projection. In line with Brans and De Smet [11] the quality better than $80 \%$ is absolutely acceptable. 
The GAIA plane can be interpreted as follows. The criteria (originally the axis) are projected as the vectors with the origin in $[0,0]$, and alternatives are displayed as points in the plane. (a) If an alternative point in a similar direction as a criterion, then the alternative performs well in this criterion and vice versa, (b) If two alternatives are close to each other, they have similar profiles (and vice versa), (c) The longer a criterion vector (axis), the more discriminating criterion and vice versa, (d) Criteria which express similar preferences point in similar directions (and vice versa).

\section{INPUT DATA}

The input data sets for the study were obtained from official UN sources, namely from the UN Global Compact database (see [10]). This database gives information about sustainability strategies and operations of involved companies and non-business organizations. There are more than 17,000 members from around the world involved, from which more than 15,000 are active members. There are 7 basic parameters in the database according to which it is possible to filter the desired results [12]:

- $\quad$ Type - the type of the member (e.g., company, NGO, city).

- $\quad$ Tier - the tier of the involvement (signatory or participant).

- $\quad$ Platform - the platform in which member can be involved (e.g., Peace, Justice and Strong Institutions, Water Resilience Coalition).

- Initiative - the initiative in which member can be involved (e.g., Business Ambition for $1.5^{\circ} \mathrm{C}, \mathrm{GC} 100$, Carbon Pricing Champions).

- $\quad$ County - the country where the member $\mathrm{HQ}$ is located (all UN member states).

- $\quad$ Sector - the sector of member (business) interest (20 sectors and 42 sub-sectors).

- $\quad$ Status - the status of communication with UN Global Compact (Active or Non-communicating).

For the study, the active members from the sector Basic resources and further subsector Industrial Metals \& Mining where selected. This filter provided 133 members for further study. All members in that selection were either Companies (65) or Small or Medium-sized Enterprises (38). The geographical distribution can be seen in Figure 2.

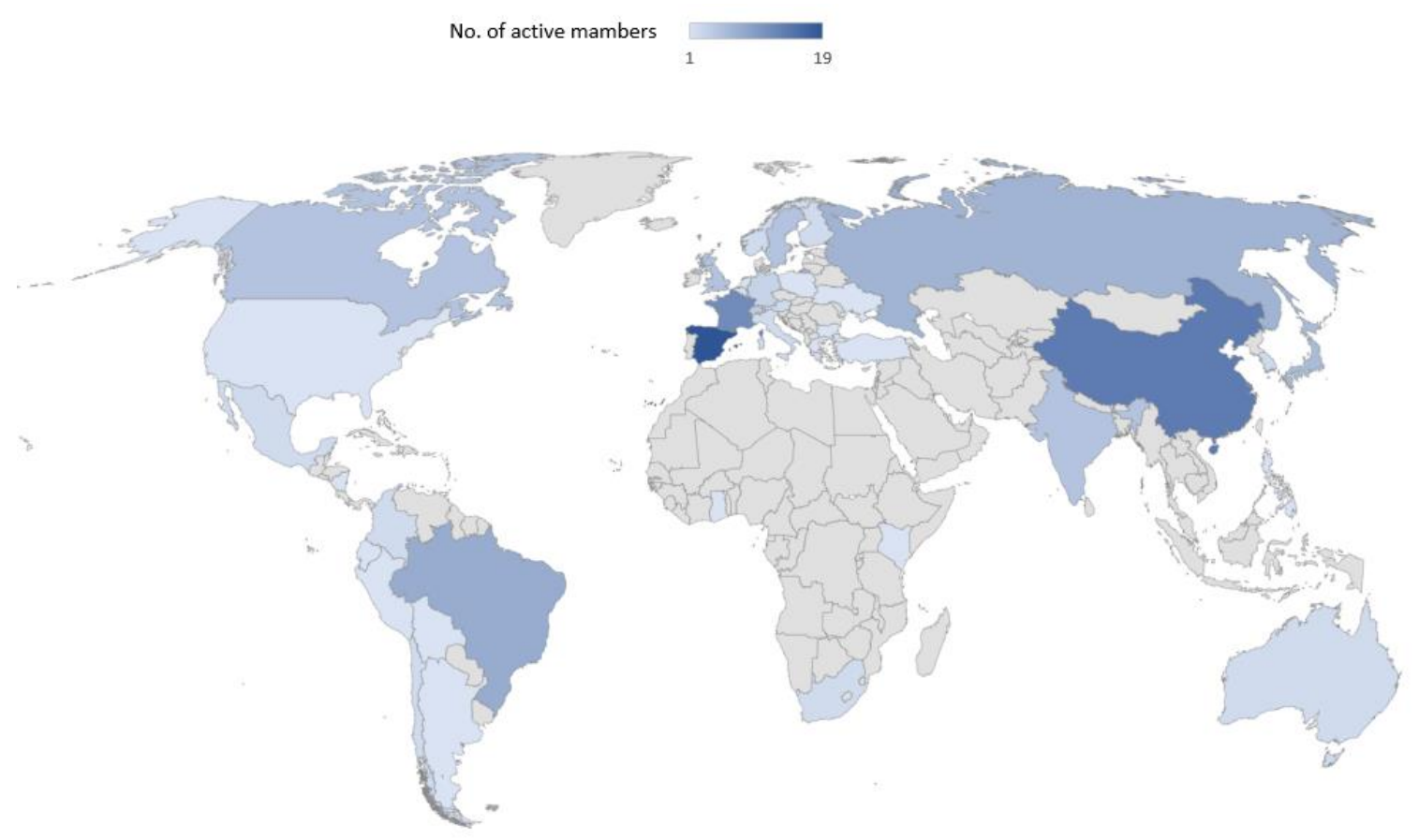

Figure 2 The geographical distribution of active members in subsector Industrial Metals \& Mining 
Each active member should submit to the database the Communication on Progress (COP), which includes answer to the following question: "Which of the following Sustainable Development Goals (SDGs) do the activities described in your COP address?". By answering this question, members proclaim which SDGs are in their focus. In the analysed subsector 103 members provided answers to this question and binary values were obtained from their reports. The absence of answers is especially noticeable for newly involved members (17 of 20 members involved in the last 365 days) who have not yet sent the first COP report. Remaining 13 members skip this part of the report continuously. Further 3 members did not mark any SDG and were therefore removed from the analysis.

The remaining 100 members were divided according to the economy conditions (EC) of their HQ country, which was a basic parameter in further research. Four categories according to UN [13] were defined: G7, developed economies, economies in transition and developing economies. The division of members in terms of economy conditions of their HQ country is as follows: major developed economies (G7) 26, developed economies (DD) 31, economies in transition (EIT) 7, and developing economies (DNG) 36.

To get the performance values for the chosen categories, the arithmetic mean of binary values was used, i.e., the relative frequency with which the companies in the particular countries follow the given SDG (e.g., the value of 0.1 means that $10 \%$ of companies in the countries with selected economy conditions follows the specific SDG and $90 \%$ do not). The resulting input data are provided in Table 1.

Table 1 Input data for the analysis

\begin{tabular}{|c|c|c|c|c|c|c|c|c|c|}
\hline EC/SDG & $\begin{array}{c}\text { No. } \\
\text { Members }\end{array}$ & SDG 1 & SDG 2 & SDG 3 & SDG 4 & SDG 5 & SDG 6 & SDG 7 & SDG 8 \\
\hline G7 & 26 & 0.27 & 0.23 & 0.54 & 0.62 & 0.73 & 0.54 & 0.73 & 0.85 \\
\hline DD & 33 & 0.21 & 0.12 & 0.62 & 0.50 & 0.47 & 0.53 & 0.56 & 0.76 \\
\hline EIT & 7 & 0.43 & 0.14 & 1.00 & 0.86 & 0.43 & 0.86 & 0.71 & 1.00 \\
\hline DNG & 36 & 0.67 & 0.44 & 0.92 & 0.83 & 0.81 & 0.83 & 0.72 & 0.94 \\
\hline EC/SDG & SDG 9 & SDG 10 & SDG 11 & SDG 12 & SDG 13 & SDG 14 & SDG 15 & SDG 16 & SDG 17 \\
\hline G7 & 0.69 & 0.38 & 0.38 & 0.81 & 0.69 & 0.15 & 0.46 & 0.46 & 0.42 \\
\hline DD & 0.71 & 0.44 & 0.35 & 0.74 & 0.79 & 0.21 & 0.35 & 0.47 & 0.47 \\
\hline EIT & 0.71 & 0.43 & 0.57 & 1.00 & 0.71 & 0.00 & 0.71 & 0.57 & 0.86 \\
\hline DNG & 0.83 & 0.64 & 0.64 & 0.86 & 0.89 & 0.33 & 0.69 & 0.83 & 0.78 \\
\hline
\end{tabular}

\section{RESULTS}

To perform the analysis, Visual PROMETHEE software has been applied. Linear preference functions (see Figure 1) were adopted for all the criteria (SDGs) with the same parameters $(Q=0, P=1)$. This setting allows for an easy comparison of the values across the criteria (all the performance values range from 0 to 1 ).

Frequency analysis of individual SDGs shows that metallurgical and mining industry worldwide prefer to follow these SDGs in 2020: 8 Decent work and economic growth, 12 Responsible consumption and production, 3 Good health and well-being, 13 Climate action, and 9 Industry, innovation and infrastructure. On the other hand, the following SDGs are preferred the least often: 14 Life below water, 2 Zero hunger, 1 No poverty, 10 Reduced inequalities, and 11 Sustainable cities and communities.

Figure 3 shows the GAIA plane for the analysed input data. Quality of the GAIA projection is $93.6 \%$ (calculated directly in the software), which guarantees reliable results. All country categories (alternatives) are situated in different quadrants. This means that the companies from individual country category tend to follow very 
different SDGs (criteria), which are represented by the blue vectors in the plane. Relatively large similarities in patterns of behaviour can be seen only in case of G7 and DD (developed economies) category. This result could be expected because G7 category is essentially a special subcategory of developed countries category.



Figure 3 GAIA plane

Figure 4 shows the GAIA action profiles. These profiles are based on the unicriterion flows $\phi_{k}\left(A_{i}\right)(1)$ and allow to compare one country category with all other ones. Also from these profiles is obvious that preferences of individual SDGs are similar only for G7 and DD category, but very different for DNG and EIT categories.

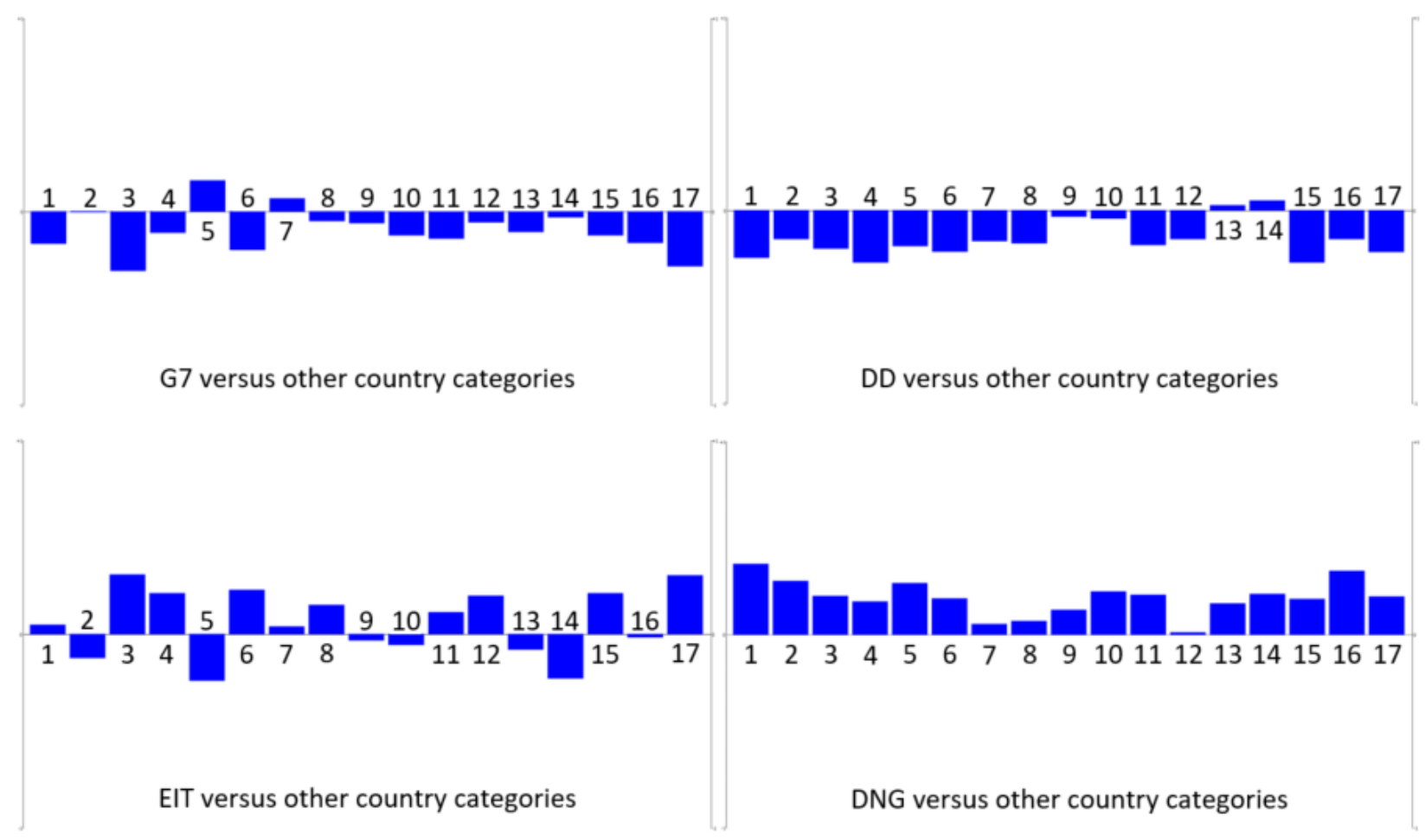

Figure 4 GAIA action profiles 
Compared to metallurgical and mining companies from other country categories:

- Companies in major developed economies (G7) relatively strongly prefer SDG 5 Gender equality. On the contrary, they do not prefer especially SDGs: 3 Good health and well-being, 17 Partnerships for the goals, 6 Clean water and sanitation, 1 No poverty, and 16 Peace, justice and strong institutions.

- $\quad$ Companies in developed economies (DD) do not have strongly preferred SDGs. However, they most often do not prefer SDGs: 4 Quality education, 15 Life on land, 1 No poverty, 17 Partnerships for the goals, and 6 Clean water and sanitation.

- $\quad$ Companies in economies in transition (EIT) strongly prefer SDGs: 3 Good health and well-being, 17 Partnerships for the goals, 6 Clean water and sanitation, 4 Quality education, 15 Life on land, and 12 Responsible consumption and production. On the contrary, they do not prefer especially SDGs: 5 Gender equality and 14 Life below water.

- Companies in developing economies (DNG) prefer all SDGs, but more strongly: 1 No poverty, 16 Peace, justice and strong institutions, 2 Zero hunger, and 5 Gender equality.

\section{CONCLUSIONS}

Worldwide SDGs preferences reflect the character of the metallurgical and mining industry. The industry is very capital-intensive (SDG 8), requires large row materials and energy resources (SDG 12), belongs to the larger employers with a high risk of injury (SDG 3), is one of the biggest polluters (SDG 13), and needs huge technological and environmental investments for its prosperity (SDG 9).

However, the research shows large differences in preferences depending on the economic country conditions in which these companies operate. It is obvious that companies from developing economies strongly prefer existential SDGs that pose pressing problems for their countries, such as poverty, hunger or military conflicts, especially in comparison with major developed and developed economies. At the same time, the companies from economies in transition more often prefer developing SDGs concerning health, education, partnerships or responsibility. Preferences of companies from major developed and developed countries are very similar and they show no strong preferences compared to companies from other economies.

Conducted research has two limitations that can negatively affect the results mentioned conclusions: (1) Number of companies from economies in transition is probably not statistically significant, (2) Classification of companies is based on $\mathrm{HQ}$ country, but their main business may come from countries with different economic conditions or some companies can operate globally.

\section{ACKNOWLEDGEMENTS}

The work was supported by the specific university research of Ministry of Education, Youth and Sports of the Czech Republic at VSB - Technical University of Ostrava, projects no. SP2021/43 and SP2021/71.

\section{REFERENCES}

[1] EUROPEAN COMMISSION. Corporate Sustainability Reporting. [online]. 2021 [viewed: 2021-05-12]. Available from: https://ec.europa.eu/info/business-economy-euro/company-reporting-and-auditing/companyreporting/corporate-sustainability-reporting en.

[2] KORCA, B., COSTA, E. Directive 2014/95/EU: building a research agenda. Journal of Applied Accounting Research. 2021, vol. 22, no. 3, pp. 401-422.

[3] PIZZI, S., ROSATI, F., VENTURELLI, A. The determinants of business contribution to the 2030 Agenda: Introducing the SDG Reporting Score. Business Strategy and the Environment. 2021, vol. 30, no. 1, pp. 404-421. 
[4] ROSATI, F., FARIA, L.G.D. Addressing the SDGs in sustainability reports: The relationship with institutional factors. Journal of Cleaner Production. 2019, vol. 215, pp. 1312-1326.

[5] UNITED NATIONS. Sustainable Development Goals, Knowledge Platform [online]. 2015 [viewed 2021-05-12]. Available from: https://sustainabledevelopment.un.org/.

[6] PILLAI, K.V. et al. Companies' accountability in sustainability: A comparative analysis of SDGs in five countries. In: Sustainable development goals in the Asian context. Singapore: Springer, 2017, pp. 85-106.

[7] YAMANE, T., KANEKO, S. Impact of raising awareness of Sustainable Development Goals: A survey experiment eliciting stakeholder preferences for corporate behavior. Journal of Cleaner Production. 2021, vol. 285, paper no. 125291.

[8] VAN DER WAAL, J.W.H., THIJSSENS, T. Corporate involvement in sustainable development goals: exploring the territory. Journal of Cleaner Production. 2020, vol. 252, paper no. 119625.

[9] LENORT, R., ZAPLETAL, F., WICHER, P., SHMELEVA, N. Sustainability Development Goals Preferences in Metallurgical and Mining Industry. In: METAL 2020: 29th International Conference on Metallurgy and Materials. Ostrava: TANGER, 2020, pp. 1249-1254.

[10] MARESCHAL, B., BRANS, J.P., VINCKE, P. PROMETHEE: A New Family of Outranking Methods in Multicriteria Analysis. Bruxelles: Universite Libre de Bruxelles, 1984.

[11] BRANS, J.P., DE SMET, Y. PROMETHEE Methods. In: Multiple Criteria Decision Analysis. New York: Springer, 2016, pp. 187-219.

[12] UNITED NATIONS GLOBAL COMPACT. Our Participants. [online]. 2021 [viewed 2021-05-12]. Available from: https://www.unglobalcompact.org/what-is-gc/participants/.

[13] UNITED NATIONS. World Economic Situation and Prospects. New York: United Nations, 2020. 